See discussions, stats, and author profiles for this publication at: https://www.researchgate.net/publication/327658936

\title{
Development and characterization of multilayer laser cladded high speed steels
}

Article $\cdot$ September 2018

DOI: 10.1016/j.addma.2018.09.009

CITATION

1

10 authors, including:

Q2)

Matthijn de Rooij

University of Twente

87 PUBLICATIONS 608 CITATIONS

SEE PROFILE

Mario Sinnaeve

Marichal Ketin

27 PUBLICATIONS 45 CITATIONS

SEE PROFILE

Some of the authors of this publication are also working on these related projects:

Project RECYLCLAD - Convention RW 11-1-7335 - GREENOMAT Call (2011-2016) View project

Project contact modelling View project
READS

129

Gisele Walmag

CRM Group

29 PUBLICATIONS 56 CITATIONS

SEE PROFILE 


\title{
Development and characterization of multilayer laser cladded high speed steels
}

\author{
N. Ur Rahman ${ }^{\mathrm{a}, *}$, L. Capuano ${ }^{\mathrm{a}}$, A. van der Meer $^{\mathrm{a}}$, M.B. de Rooij ${ }^{\mathrm{b}}$, D.T.A. \\ Matthews $^{\mathrm{c}}$, G. Walmag ${ }^{\mathrm{d}}$, M. Sinnaeve ${ }^{\mathrm{e}}$, A. Garcia ${ }^{\mathrm{f}}$, M. Castillof ${ }^{\mathrm{f}}$, G.R.B.E. \\ Römer ${ }^{\mathrm{a}}$ \\ ${ }^{a}$ Chair of Laser Processing, Department of Mechanics of Solids, Surfaces \& Systems \\ $\left(M S^{3}\right)$, Faculty of Engineering Technology, University of Twente, Enschede, The \\ Netherlands \\ ${ }^{b}$ Chair of Surface Technology \& Tribology, Department of Mechanics of Solids, Surfaces \\ E Systems $\left(M S^{3}\right)$, Faculty of Engineering Technology, University of Twente, Enschede, \\ The Netherlands \\ ${ }^{c}$ Chair of Skin Tribology, Department of Mechanics of Solids, Surfaces $\mathcal{E}$ Systems (MS ${ }^{3}$ ), \\ Faculty of Engineering Technology, University of Twente, Enschede, The Netherlands \\ ${ }^{d}$ CRM Group, Metal Processing Technology, Rue des Ples 1 B56-Quartier Polytech 2 \\ B-4000 Liege, Belgium \\ ${ }^{e}$ Marichal Ketin, Rue Ernest Solvay 372, 4000 Liege, Belgium \\ ${ }^{f}$ IMDEA Materials Institute, Tecnogatafe, Madrid, Spain
}

\section{Abstract}

Two high speed steel (HSS) alloys were laser cladded on $42 \mathrm{CrMo}_{4}$ steel cylindrical substrate by using a $4 \mathrm{~kW} \mathrm{Nd:YAG} \mathrm{laser} \mathrm{source.} \mathrm{After} \mathrm{optimiza-}$ tion of the laser material processing parameters for single layers, multilayered clads were produced. Microstructural characterization of the laser deposits constitutes studies of the carbides and matrix, which was done by using Scanning Electron Microscopy (SEM), Energy Dispersive Spectroscopy (EDS), Electron Backscattered Diffraction (EBSD) and High Resolution Transmission Electron Microscopy (HRTEM).

The strengthening mechanism of LC1 (Fe-Cr-Mo-W-V) was comprised of a martensitic matrix and retained austenite along with networks of $\mathrm{VC}$ and $\mathrm{Mo}_{2} \mathrm{C}$ eutectic carbides. Cr enriched fine carbides $\left(\mathrm{Cr}_{7} \mathrm{C}_{3}\right.$ and $\left.\mathrm{Cr}_{23} \mathrm{C}_{6}\right)$ were embedded within the matrix. During laser cladding of the multilayer

\footnotetext{
*Corresponding author at: P.O. Box 217, 7500 AE, Enschede, The Netherlands Email address: n.naveedurrahman@utwente.nl (N. Ur Rahman)
} 
deposits, cladding of subsequent layers had a detrimental effect on the hardness of previously cladded layers, which was due to tempering of existing lath martensite. To overcome the hardness drop, a new alloy LC2 (Fe $\mathrm{F}_{b a l-x}-\mathrm{Cr}-\mathrm{Mo}-$ $\mathrm{W}-\mathrm{V}-\mathrm{Co}_{x}$ ) was blended by addition of $3-5 \%$ of Co in LC1. The addition of Co resulted in an overall increase in hardness and a reduction in the hardness drop during sequential layer cladding; the latter was due to the presence of Co in the solid solution with Fe.

High Resolution Transmission Electron Microscopy (HRTEM) was performed to characterize the nanometer-sized precipitates evolved during the reheating. These carbides were either enriched with $\mathrm{V}$ and $\mathrm{W}$ or formed from a complex combination of $\mathrm{V}, \mathrm{Mo}, \mathrm{W}$ and $\mathrm{Cr}$ with lattice spacings of $0.15 \mathrm{~nm}$ to $0.26 \mathrm{~nm}$.

Keywords: High speed steel, Laser cladding, Complex nanometer-sized carbides, Compressive residual stress, Crack propagation

\section{Introduction}

The laser cladding is a manufacturing technique, which uses absorbed laser energy to deposit clad layers of improved properties onto a given substrate [1, 2]. The clad material can be deposited by several ways, among which powder injection is found most effective in most cases [3]. That is, during laser cladding a high power laser beam scans over the surface of the substrate creating a melt pool and powder material is simultaneously injected into the melt pool to produce clad tracks upon solidification [4]. The process parameters like laser power, laser scan speed, powder mass flow rate, preheating temperature, carrier and shielding gas flow rates have strong influence on the clad quality [5]. Laser cladding offers distinct processing advantages over conventional technologies due to high control over the heat input, limited heat affected zone (HAZ), minimal dilution of the powder material with substrate and low distortion, and strong bonding between clad layers and the substrate [6, 7]. Laser cladding process is also known as Direct Metal Deposition (DMD), Laser Metal Deposition (LMD) and Direct Energy Deposition (DED) [8]

In applications where exceptional properties like wear and corrosion resistance, high strength and hardness are required, high speed steels (HSS) are highly preferred materials [9, 10]. These alloys therefore are extensively used in a variety of applications such as cutting tools, high speed machining, 
hot stamping, moulding and hot rolling [11]. HSS are complex alloy steels containing carbide forming elements like vanadium, tungsten, molybdenum and chromium, with the alloying elements percentage ranges usually between $10-25 \%$ [12].

For hot strip mill (HSM), HSS work rolls are conventionally produced by the casting process [13, 14]. Typical microstructe of the cast HSS rolls is composed of martensitic matrix and heterogeneously distributed coarser grain boundary carbides with the grain size ranging from 20-200 $\mu \mathrm{m}$ [15, 16]. Nilsson et al. [17] recommends the utilization of powder metallurgy processes to refine the microstructure. Microstructural refinement will improve the thermo-mechanical fatigue and the wear resistance of the work rolls in the HSM. Such refinement of the microstructure can be achieved by laser cladding process as of relatively high cooling rates [18, 19].

Although rapid cooling during re-solidification results in superior mechanical and metallurgical properties of deposited laser clads, it can also induces high residual stresses after deposition [20]. Moreover, by stacking clad layers on top of each other, and with the increase of hardness above $500 \mathrm{HV}$, it is quite difficult to produce crack free clad tracks [21]. In the case of HSS, due to the presence of martensitic matrix and hard carbides like MC (2500 $\mathrm{HV}), \mathrm{M}_{2} \mathrm{C}(2000 \mathrm{HV}), \mathrm{M}_{7} \mathrm{C}_{3}(1600 \mathrm{HV}), \mathrm{M}_{6} \mathrm{C}(1500 \mathrm{HV})$ and $\mathrm{M}_{23} \mathrm{C}_{6}(1000$ $\mathrm{HV}$ ) carbides [22], the overall hardness can be higher than $800 \mathrm{HV}$, making it further difficult to produce thick multilayer clad coatings. In that case preheating of the substrate is an approach to reduce cooling rates during cladding of metal alloys, which are highly susceptible to cracking resulting in achieving homogeneous clad properties [23, 24].

In the past, multilayer laser cladding of commercially available HSS alloys with relatively small thickness was studied by Shim et al. [25] and Ocelik et al. [26]. Various studies were conducted to identify the nano- precipitates evolved during heat treatment of cast HSS alloys [27-29] and identified the nano- precipitates as $\mathrm{M}_{7} \mathrm{C}_{3}$ and $\mathrm{M}_{23} \mathrm{C}_{6}[28,29]$. The current work emphasizes the development of relatively thick homogeneous multilayer laser cladding of HSS alloys (up to $20 \mathrm{~mm}$ thickness), and provides a detailed study of microstructure in terms of phase constitution and micro-hardness. In addition, High Resolution Transmission Electron Microscopy (HRTEM) characterizes the nanometer-sized complex carbides in the matrix precipitated during the re-heating of intermediate layers. 


\section{Experimental}

\subsection{Experimental setup and processing parameters}

The laser cladding setup used consists of a $4 \mathrm{~kW} \mathrm{cw} N d$ :YAG laser source (Trumpf) equipped with a transport fibre of $600 \mu \mathrm{m}$ core diameter. The focusing head consisting of a $200 \mathrm{~mm}$ collimation lens and a $300 \mathrm{~mm}$ focal lens, which was mounted to the end-effector of a six degree of freedom ABB robot IRB-2600M2004, see fig.1. An ABB tilt rotation manipulator was used to manipulate the cylindrical substrates. The powder was supplied by a Twin150C Oerlikon-Metco powder feeder and injected into the laserinduced melt pool on the substrate by lateral nozzles of $2.5 \mathrm{~mm}$ and 3.0 $\mathrm{mm}$ in diameter. An IWS Fraunhofer thermal camera EMAqS is used for the inspection of the state of the melt pool during laser cladding. Argon was used as powder carrier gas, as well as to protect the laser-material interaction zone from oxidation.

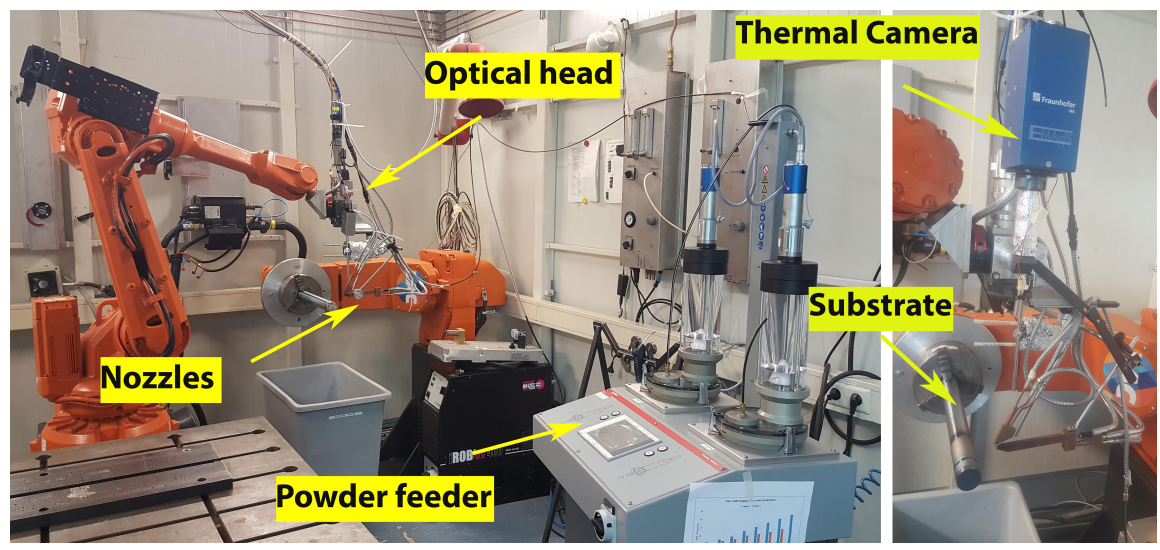

Figure 1: (L) High power laser cladding facility at the University of Twente (R) Enlarged image of optical head with an EMAqS thermal camera

To improve shielding of the clad layer just behind the laser spot, an additional shielding gas nozzle (ILT-Fraunhofer) was used. A Metis HQ22 pyrometer of Sensortherm and handheld thermocouple were used to monitor the temperature during solidification and cooling of the laser clads. Powder injection was conducted both by stinging and dragging injections [30], see fig.2. Stinging injection configuration was preferred due to efficient shielding 


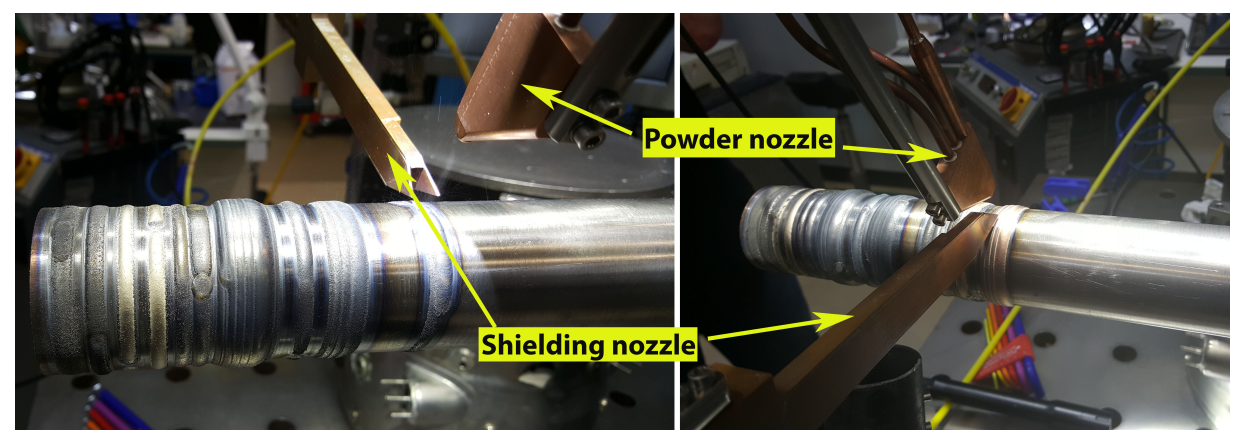

Figure 2: Different configurations of lateral powder injection and shielding gas nozzles, (L) Dragging injection (R) Stinging injection

of the track being produced. The distance of the tip of the powder nozzle from the melt pool was set to $13 \mathrm{~mm}$.

In order to limit porosities and stress concentration between consecutive tracks as well as to increase the thickness of clad layers, subsequent clad tracks were overlapped by $50 \%$ of the width of the single track. Preheating of the substrate is usually performed by induction or resistive heat sources. However, in this study the heat accumulated by the previously cladded layers is used as source of heat for cladding the next layer at a high equilibrium temperature of $150{ }^{\circ} \mathrm{C}$. Laser cladding processing parameters for the cladding of single layers as well as of multilayer laser clads are listed in Table 1 .

Table 1: Processing window for the laser cladding process

\begin{tabular}{cccc}
\hline $\begin{array}{c}\text { Laser power } \\
(\mathrm{W})\end{array}$ & $\begin{array}{c}\text { Laser scan speed } \\
(\mathrm{mm} / \mathrm{s})\end{array}$ & $\begin{array}{c}\text { Powder mass flow rate } \\
(\mathrm{g} / \mathrm{min})\end{array}$ & $\begin{array}{c}\text { Beam diameter } \\
(\mathrm{mm})\end{array}$ \\
\hline 3600 & 5 & 16 & 7 \\
$2200-2400$ & 5 & 14 & 5 \\
\hline
\end{tabular}

\subsection{Materials}

Laser cladding of two HSS alloys, LC1 (Fe-Cr-Mo-W-V) and LC2 (Fe ${\text { bal }-x^{-}}^{-}$ Cr-Mo-W-V-Co $\mathrm{Co}_{x}$ ) was performed. The chemical compositions of these alloys are listed in Table 2. Laser cladding powders were commercially purchased from Höganäs AB and Carpenter Technology Corporation and were investigated by varying the amount of carbide forming elements $\mathrm{V}, \mathrm{W}$ and Mo and 
by addition of Co (LC1 and LC2). The morphology of the LC1 powder was spherical with an average particle size of $90 \mathrm{~m}$, while the LC2 powder had asymmetric particles and satellites present with an average particle size of $70 \mu \mathrm{m}$, see fig.3. Laser cladding was performed on $42 \mathrm{CrMo}_{4}$ steel cylindrical substrates of $50 \mathrm{~mm}$ and $100 \mathrm{~mm}$ diameters.

Table 2: Chemical composition of cladding powders (Wt.\%)

\begin{tabular}{ccccccccc}
\hline Powders & C & Cr & Mo & W & Co & V & Si & Fe \\
\hline LC1 & 1.40 & 4.30 & $4.0-6.0$ & $5.0-6.0$ & - & $3.0-5.0$ & 0.40 & bal \\
LC2 & 1.40 & 4.30 & $4.0-6.0$ & $5.0-6.0$ & $3.0-5.0$ & $3.0-5.0$ & 0.40 & bal \\
\hline
\end{tabular}
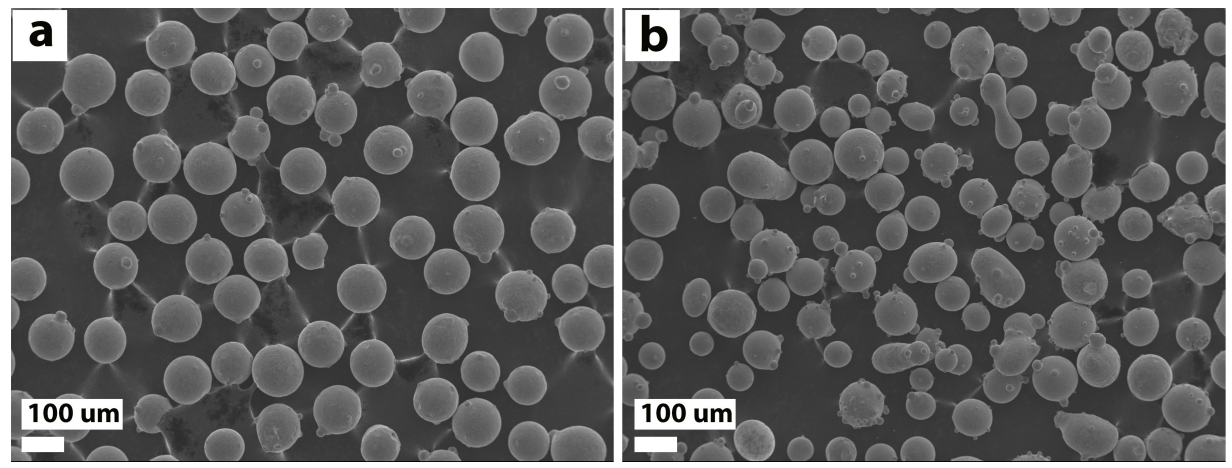

Figure 3: SEM micrographs showing the morphology of powders (a) LC1 and (b) LC2

\subsection{Analysis tools}

Samples for the microstructural analysis were prepared from the crosssections of laser cladded bars and mounted in Bakelite (Struers-PolyFast). Polishing of samples was performed on Struers TEGRAMIN-30 by using diamond suspensions of $9 \mu \mathrm{m}, 3 \mu \mathrm{m}, 1 \mu \mathrm{m}$, and $0.25 \mu \mathrm{m}$, and colloidal silica suspension of $0.04 \mu \mathrm{m}$. A JEOL JSM-7200F field emission SEM equipped with EDS and EBSD sensors was used for microstructural, elemental and phase analysis which is quantified using AZtecHKL from Oxford Instruments. A FEI Thermo Scientific ${ }^{T M}$ Talos F200X Scanning/Transmission Electron Microscope (S/TEM) was used for HRTEM imaging. Samples for HRTEM were prepared by Focused Ion Beam (FIB). 
The micro-hardness of the HSS alloys was determined by a Leco LM100AT Vickers indenter. The micro-hardness measurements were conducted at a load of $500 \mathrm{~g}$ with a dwell time of $15 \mathrm{~s}$ (DIN EN ISO 6507-1 standard). Tensile testing of $20 \mathrm{~mm}$ thick laser cladded samples of LC1 was conducted to access the bonding of clad with the substrate. The tensile testing was performed at room temperature by a Universal Tensile Testing Machine. Cylindrical samples of $39 \mathrm{~mm}$ in length were machined from the $20 \mathrm{~mm}$ thick laser clad on $100 \mathrm{~mm}$ diameter rod by wire Electrical Discharge Machining (EDM). Samples were machined in such a way that half of the sample consisted of laser clad while the other half consisted of substrate material.

\section{Results}

\subsection{Multilayer deposition}

During the laser cladding trials aiming at the deposition of multilayer clads of HSS alloys, two parameters were found to be of critical importance, the height of individual clad layers and the substrate temperature. Depositing relatively thick individual clad layers in order to limit the total number of clad layers, reduces the risk of interlayer defects and number of starts and stops. At the same time preheating prevents cracking and delamination of clad layers which occurred while cladding at room temperature, see fig 4 .

Thick multilayer laser clads ( $4 \mathrm{~mm}, 10 \mathrm{~mm}$ and $20 \mathrm{~mm}$ ) of LC1, which were successfully produced by maintaining a high equilibrium temperature of $150{ }^{\circ} \mathrm{C}$ (fig.4). The $20 \mathrm{~mm}$ thick laser clads were deposited with help of eleven overlapping clad layers. The relative velocity of the laser beam to the

surface of the substrate was fixed at $5 \mathrm{~mm} / \mathrm{s}$, as previously no considerable effect of higher processing beam velocities was found on hardness during processing of HSS alloys [31]. For micro-hardness comparison and to observe possible tempering effects due to sequential cladding, double layer $(4 \mathrm{~mm}$ thick) coatings of LC1 and LC2 were laser cladded.

\subsection{Microstructural investigation}

Fig 5 shows the Backscattered Electron (BSE) micrographs of the crosssections of LC1 and LC2. The microstructures of both alloys consist of interdendritic networks of eutectic carbides and martensitic matrices along with retained austenite. BSE micrographs show the typical size and morphology of different carbides present in the laser clad HSS alloys, see fig 6 . It is found that MC (VC) carbides are blocky, round and rod like shaped 

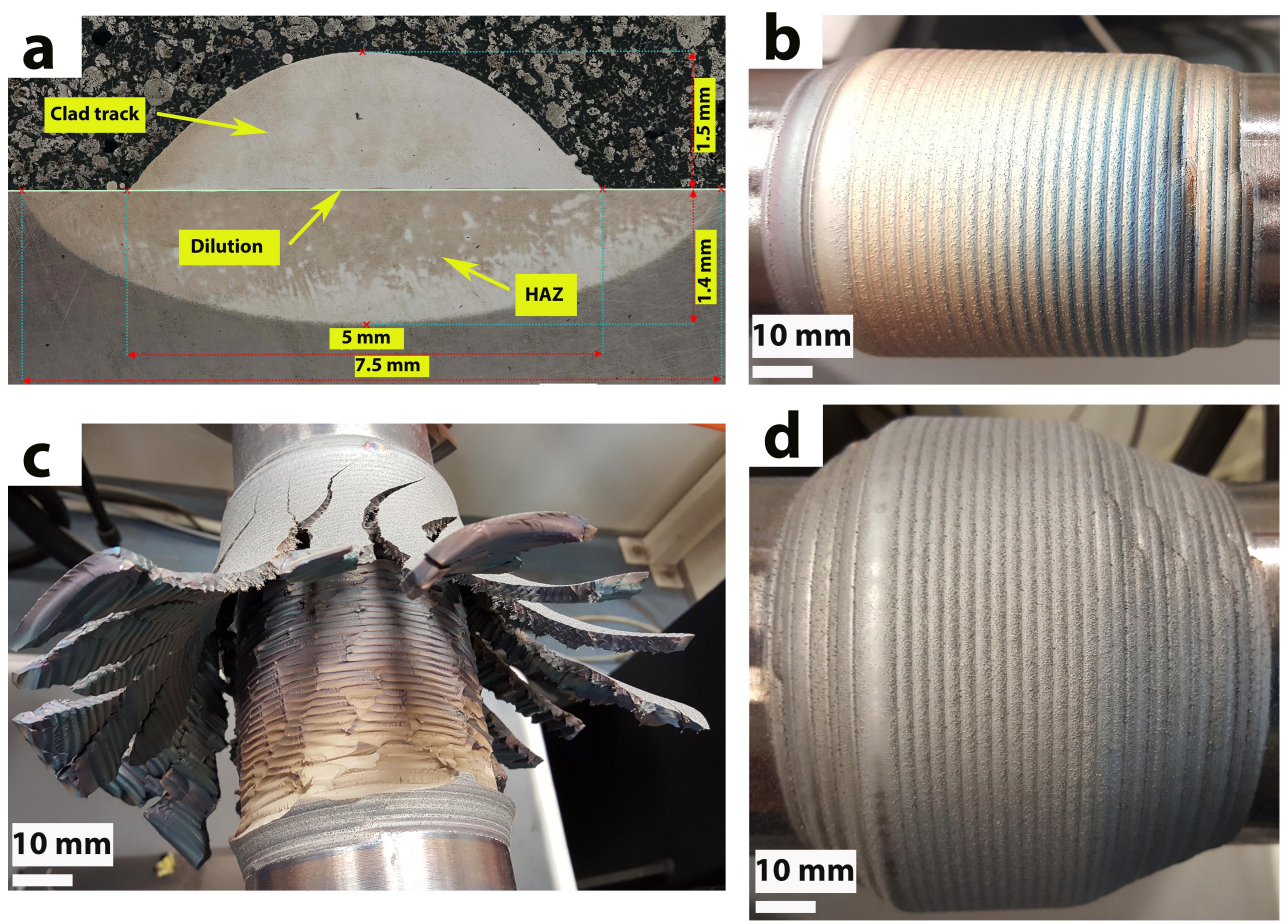

Figure 4: Photographs of single and multilayer laser depositions (a) Cross section of a single clad track of LC1, showing clad, dilution and HAZ, (b) $4 \mathrm{~mm}$ thick coating of LC2, (C) Cracking of multilayer sample cladded of LC1 at room temperature, and (d) $20 \mathrm{~mm}$ thick coating of $\mathrm{LC} 1$ cladded at $150{ }^{\circ} \mathrm{C}$

and are enriched with $\mathrm{V}$. While $\mathrm{M}_{2} \mathrm{C}$ carbides have feathery, lamellar and layered morphology and are enriched with Mo [16], (fig 6). Fine $\mathrm{Cr}$ enriched secondary precipitates of $\mathrm{M}_{7} \mathrm{C}_{3}$ and $\mathrm{M}_{23} \mathrm{C}_{6}$ are embedded in the matrix. For $\mathrm{LC} 2,3-5 \%$ Co is added to the $\mathrm{LC} 1$. The additional Co does not form carbides but is uniformly dispersed in the martensitic matrix [32].

Table 3: Phase constitution of HSS alloys by EBSD analysis (\%)

\begin{tabular}{cccccc}
\hline Materials & Martensite & $\mathrm{VC}$ & $\mathrm{Mo}_{2} \mathrm{C}$ & $\mathrm{Cr}_{7} \mathrm{C}_{3} \& \mathrm{Cr}_{23} \mathrm{C}_{6}$ & $\mathrm{Co}$ \\
\hline LC1-L1 (upper layer) & 72 & 14 & 8 & 6 & - \\
LC1-L2 (lower layer) & 75 & 12 & 8 & 5 & - \\
LC2 & $72-74$ & 11 & 7 & 5 & bal \\
\hline
\end{tabular}


EBSD analysis of both alloys was performed to study their strengthening mechanisms. Fig.7 shows the phases present in the LC1. Due to the crystallographic similarity, $\mathrm{VC}$ carbides and austenite are indexed together. After martensite, the larger proportion was comprised of $\mathrm{VC}, \mathrm{Mo}_{2} \mathrm{C}$ and $\mathrm{Cr}_{23} \mathrm{C}_{6}$ carbides. A phase fraction comparison of upper (L1) and lower (L2) layers of LC1 is listed in Table 3. Due to re-heating during the multilayer deposition, the amount of secondary precipitates varies from the bottom to the top layer. This re-heating resulted in transformation of residual austenite to martensite, due to which the phase fraction of martensite is greater in L2 when compared to L1. Inverse pole figures (IPF) indicated a heterogeneous distribution of grain orientations, see fig.7b and c.
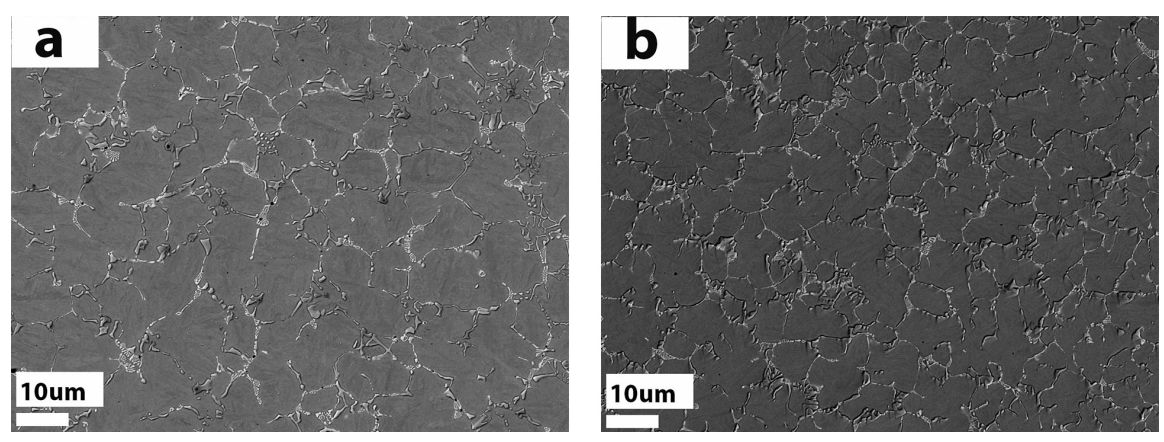

Figure 5: BSE micrographs showing the dendritic microstructure of (a) LC1 and (b) LC2
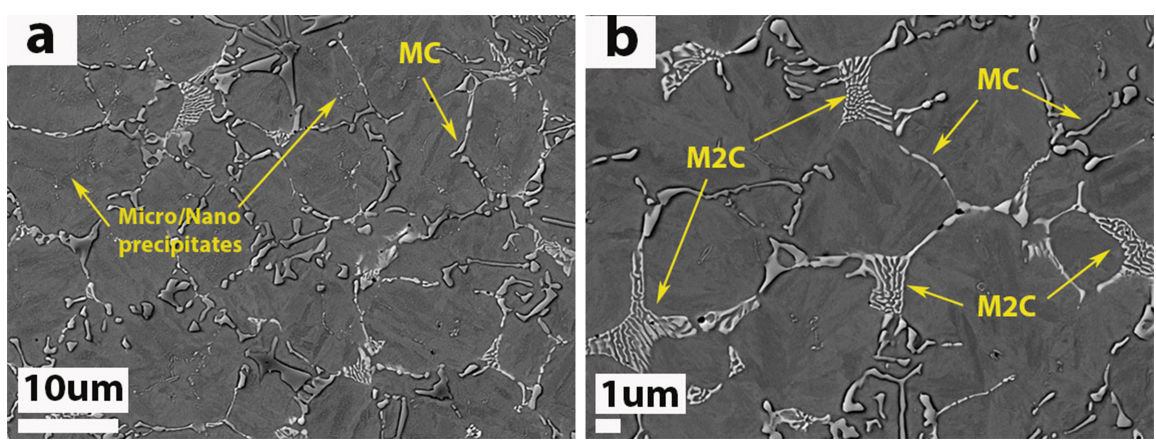

Figure 6: BSE micrographs showing different carbides present in LC1 and LC2, (a) Rod and angular shaped MC carbides, and micro/nanometer size precipitates (b) Lamellar and layered type $\mathrm{M}_{2} \mathrm{C}$ carbides 

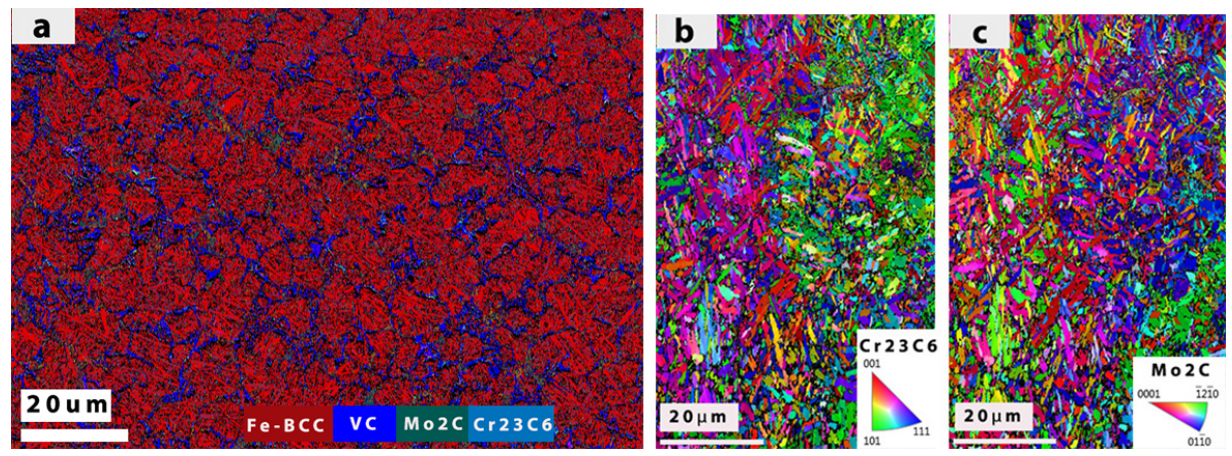

Figure 7: (a) EBSD phase map of LC1, (b) and (c) Inverse pole figures (IPF) showing heterogeneous grain orientations
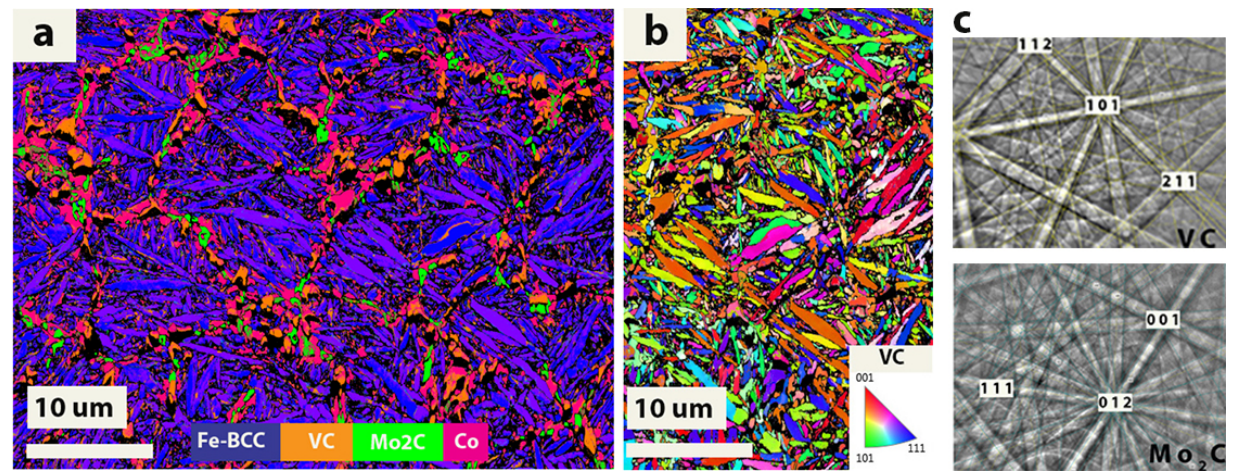

Figure 8: (a) EBSD phase map of LC2, (b) IPF showing the heterogeneous grain orientations and (c) Indexed patterns of $\mathrm{VC}$ and $\mathrm{Mo}_{2} \mathrm{C}$ carbides

Fig 8 a, b, and $c$ show the phases present in LC2, IPF mapping and the corresponding Kikuchi patterns respectively. Similar to the LC1, the phase fraction of LC2 also consisted of $\mathrm{VC}, \mathrm{Mo}_{2} \mathrm{C}$ and $\mathrm{Cr}_{23} \mathrm{C}_{6}$ carbides. EBSD analysis revealed that Co stays in the solid solution with $\mathrm{Fe}$ and also adsorbed on the surfaces of carbides [32, 33], while the rest is indexed as martensite. IPF mapping of LC2 also revealed a heterogeneous distribution of grain orientations, see fig.8 b. The phase fraction of LC2 is listed in Table 3 .

HRTEM of LC1 and LC2 samples was performed to characterize the nanometer-sized fine carbides embedded in the matrix, see fig. 10. These carbides were precipitated as a result of re-heating during laser cladding of 
subsequent layers. The morphology of these carbides particles varied from round, blocky to irregular geometrical shapes. The typical diameter/length of these carbides ranged from $5 \mathrm{~nm}$ to $500 \mathrm{~nm}$, see fig 9 . The STEM of these nanometer-sized precipitates showed that either these were enriched with $\mathrm{V}$ and $\mathrm{W}$ or formed from a complex combination of $\mathrm{V}, \mathrm{W}$, Mo and Cr. The identified lattice spacings of these precipitates were $0.15 \mathrm{~nm}, 0.22 \mathrm{~nm}, 0.25$ $\mathrm{nm}$ and $0.26 \mathrm{~nm}$, see fig. 10 .

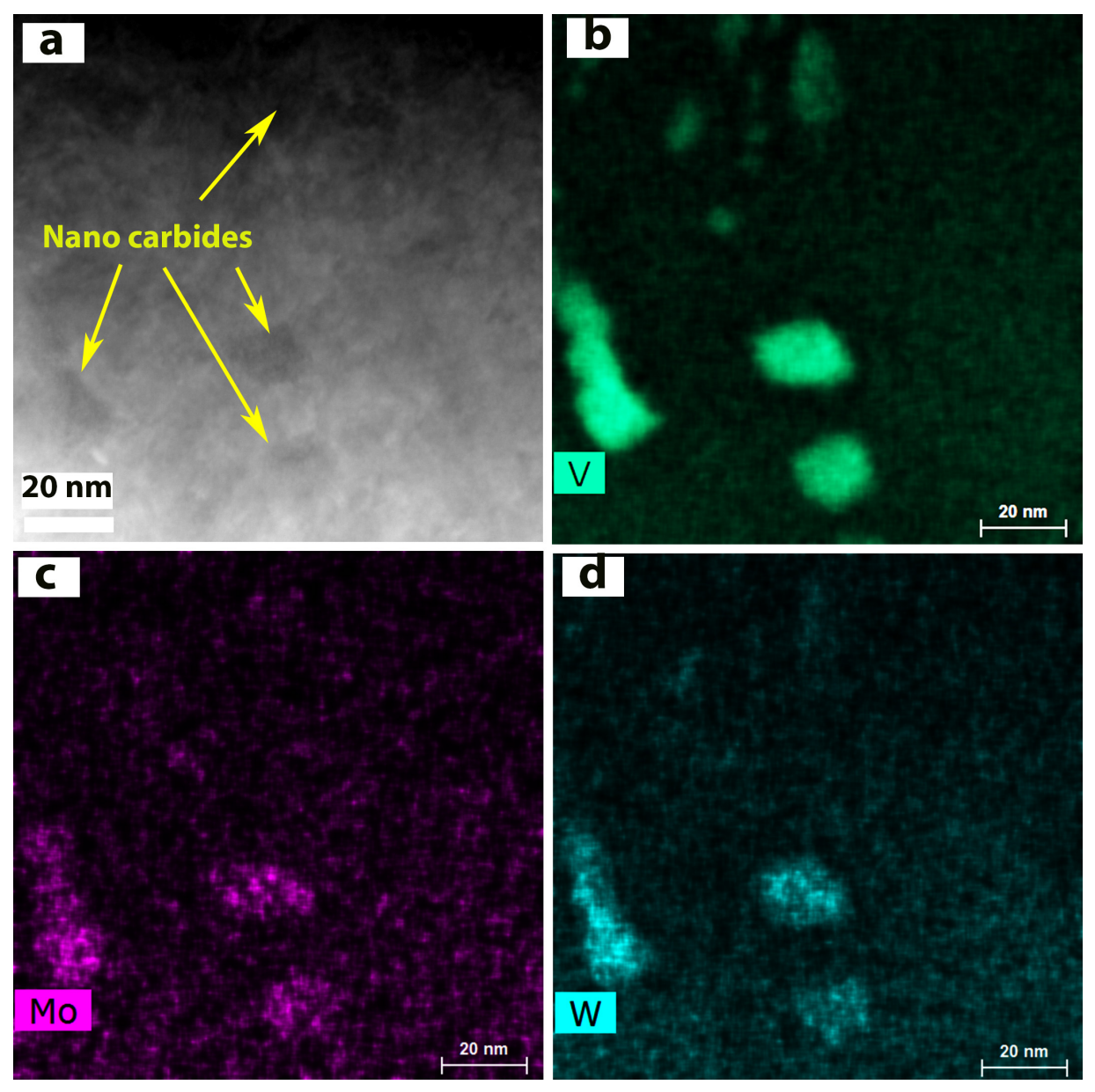

Figure 9: (a) TEM micrograph of the nanometer-sized precipitates in LC2, (b), (c) and (d) STEM analysis of the nanometer size precipitates shown in (a) confirming the enrichment of these precipitates with $\mathrm{V}$ and presence of Mo and $\mathrm{W}$ 

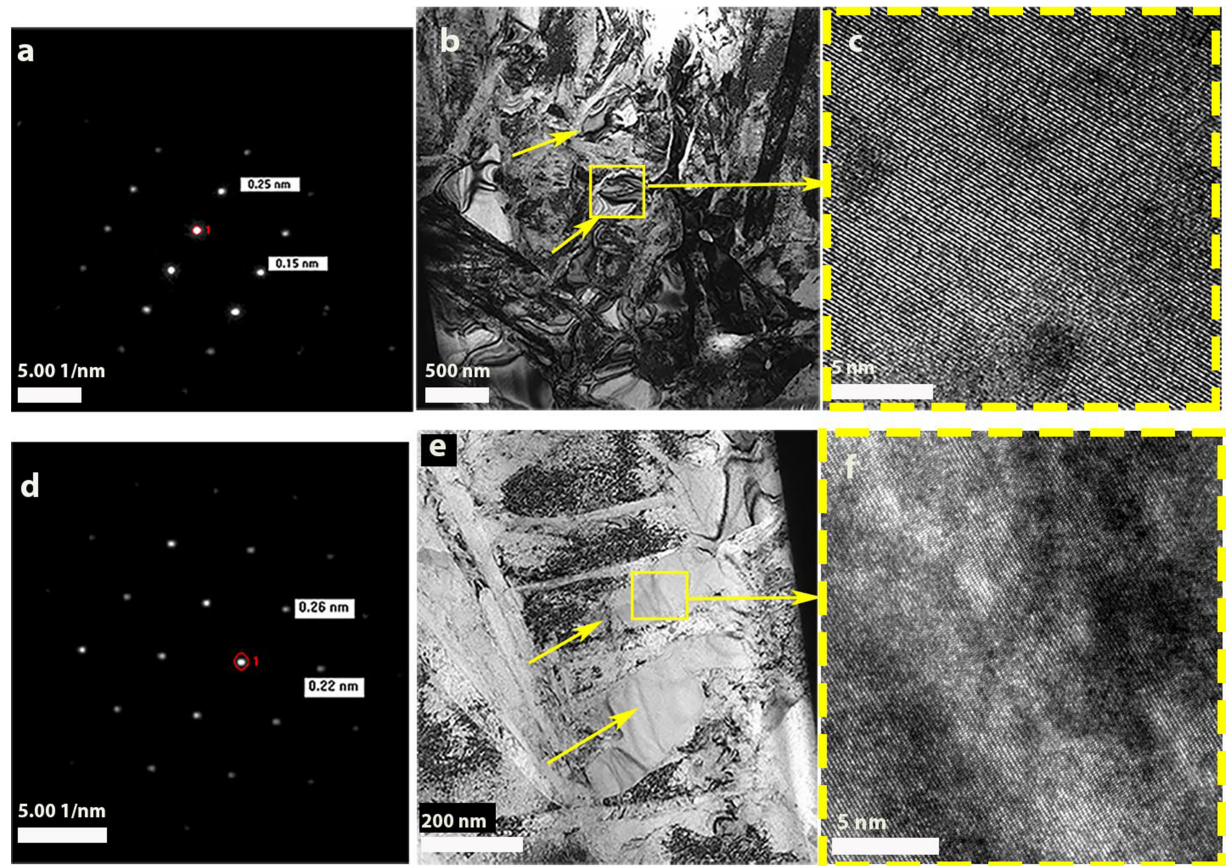

Figure 10: (a) Diffraction pattern of b, (b) TEM micrograph of the nanometer-sized precipitates enriched with V (LC1), (c) HRTEM image of the precipitate shown in b, (d) diffraction pattern of e, (e) TEM micrographs of nanometer-sized precipitates enriched with W (LC2) and (f) HRTEM image of the precipitates shown in e.

\subsection{Micro-hardness}

An assessment of the homogeneity of the multilayer coatings of LC1 and LC2 was performed in terms of the coating micro-hardness. It was found that in case of LC1, reheating left a detrimental effect on the hardness of previously cladded layer, see fig.11. For a six layers laser cladded sample of LC1 ( $\approx 10 \mathrm{~mm}$ thick), the micro-hardness of the intermediate layers dropped to a minimum value of around $570 \mathrm{HV}$ after three layers have been cladded. The top layer yielded the peak micro-hardness of $795 \mathrm{HV}$, due to the fact that it was not re-heated (fig 11).

The addition of Co in LC1 (i.e. LC2), reduced the hardness drop to a minimum value of $786 \mathrm{HV}$, along with increasing the peak micro-hardness to $843 \mathrm{HV}$. A comparison of micro-hardness measurements of double layers samples of LC1 and LC2 is given in fig.11. 

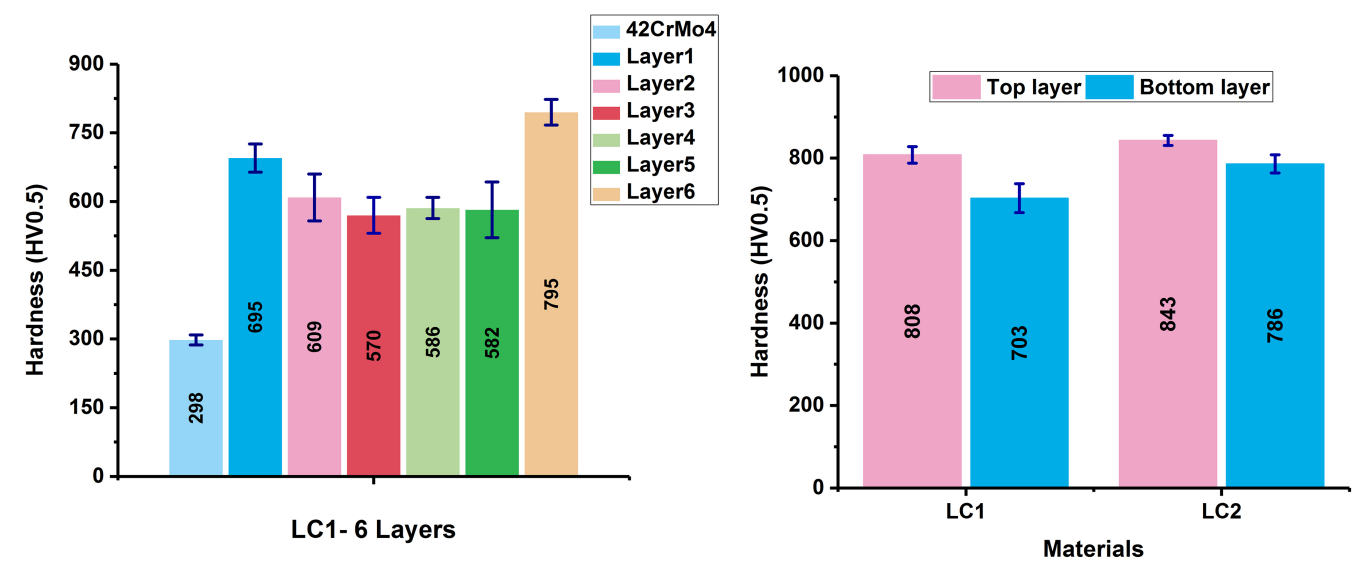

Figure 11: (L) Micro-hardness plot of 6 layers laser cladded sample of LC1, (R) Microhardness comparison of double layers laser cladded samples of LC1 and LC2

\subsection{Tensile testing}

Tensile testing was performed to evaluate the bonding between the thick multilayer coating and the substrate. For this purpose, the uniaxial tensile testing of $20 \mathrm{~mm}$ thick coating of LC1 was carried out. Tensile testing results are plotted in fig.12. The insert in fig, 12 shows the dimensions of machined samples. Tensile testing indicated the samples failure at an ultimate tensile strength of $889 \pm 20 \mathrm{MPa}$. These results reveal a strong bonding between the substrate and the clad layers. The samples were fractured in the clad region, with flat fracture surfaces. No crack propagation was reported through the interface between laser clad and substrate.

Due to the presence of martensitic matrix and hard carbides in the LC1 clad layers, a brittle failure is observed, at about $2.5 \%$ plastic strain to failure. The fractured surfaces of the tensile samples were subjected to a detailed SEM analysis, see fig.13. SEM micrographs of the fractured surface showed a presence of cleavages over the entire surface indicating the brittle failure, with a small fraction of locally induced plastic deformations (presence of dimpled morphology), see fig $13 \mathrm{a}$. Crack propagation was dominantly observed at the grain boundaries, through the eutectic, see fig $13 \mathrm{~b}$. 


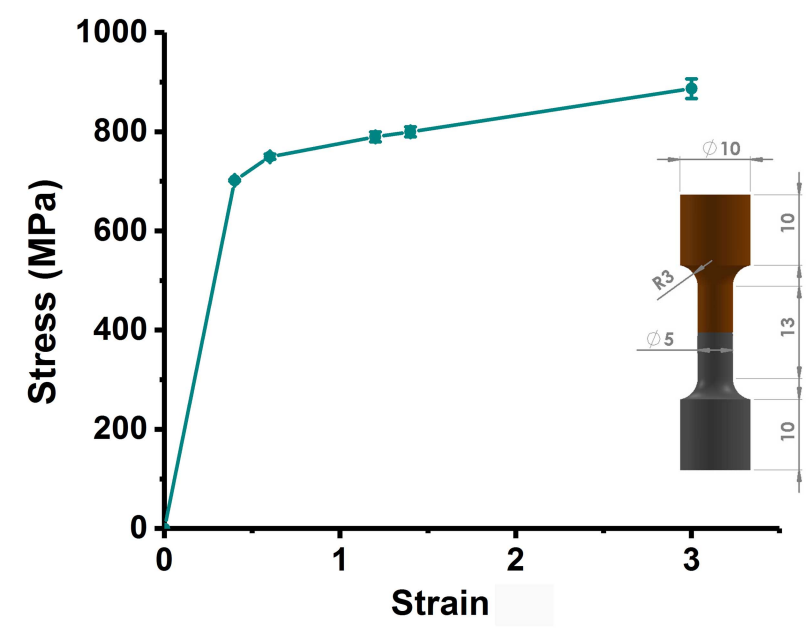

Figure 12: Stress-strain curve of LC1 laser cladded sample along with $42 \mathrm{CrMo}_{4}$ substrate. Insert: Front view of the machined sample (dimensions in $\mathrm{mm}$ )
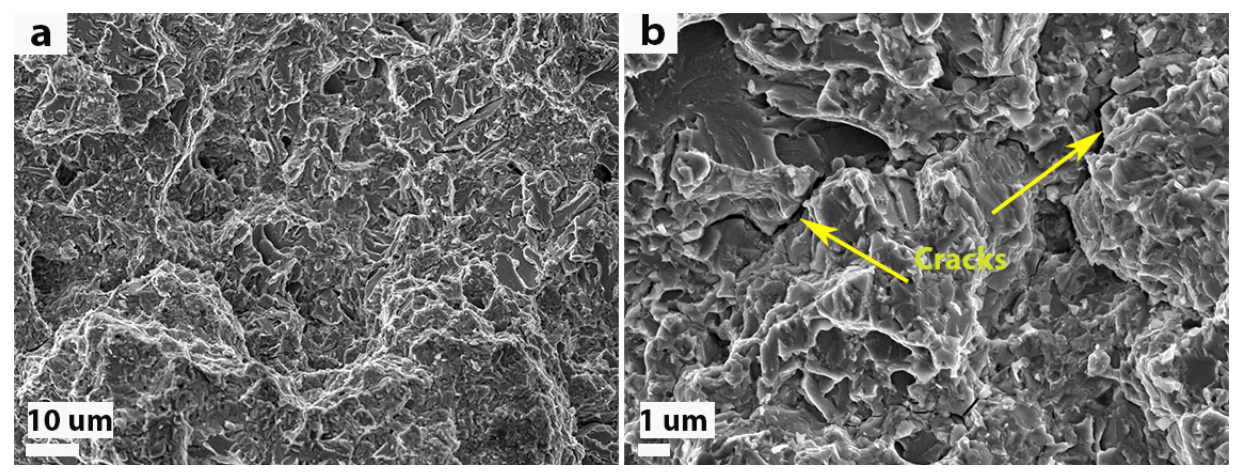

Figure 13: SEM micrographs of the fractured surface of LC1 sample, (a) Fractured surface of LC1 showing the cleavages spread over the fracture surface, (b) Crack propagation through carbide networks

\section{Discussion}

The presence of hard carbides $\left(\mathrm{MC}, \mathrm{M}_{2} \mathrm{C}, \mathrm{M}_{7} \mathrm{C}_{3}\right.$ and $\left.\mathrm{M}_{23} \mathrm{C}_{6}\right)$ and martensitic matrix in the laser processed thick multilayer coatings of HSS, make these coatings highly prone to cracking during solidification and cooling. However, in the case of LC1 and LC2 (HSS alloys), massive martensitic transformation occurs, leading to the development of compressive residual 
stresses due to expansion upon solidification [34 36]. The presence of strong compressive stress component played a vital role in the development of thick multilayer layer coatings. The presence of compressive stresses in the laser cladded LC1 is confirmed by the hole drilling method [37, 38]. The residual stress measurements was carried out by using the incremental strain method [39. The residual stress measurements showed that stresses are compressive in nature from top of the clad to the substrate, see fig.14. Similarly Bailey et al. [40] also recorded the presence of strong compressive stresses in the laser cladding of H13 HSS due to high phase fraction of martensite even after tempering. Furthermore, cladding at pre-heating temperatures $150{ }^{\circ} \mathrm{C}$ reduces the temperature gradient during the cooling phase, overcoming the risk of cracking which was observed during cladding at room temperature [24, 25], see cracking in fig 4 .
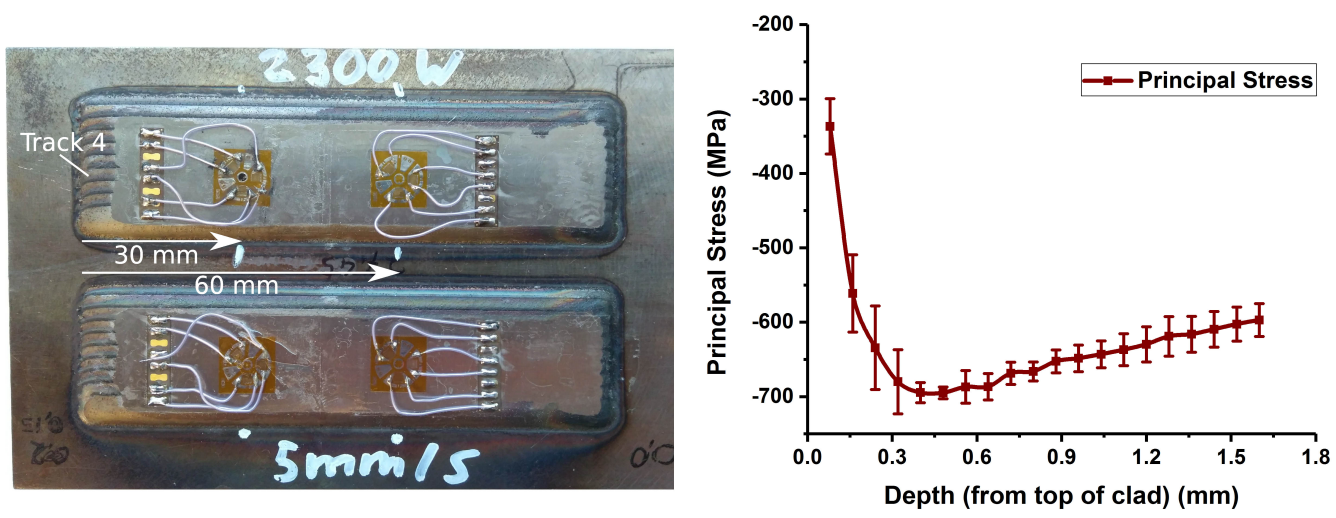

Figure 14: Residual stress measurement (L) Clad layers on a plate with strain gauges, (R) Compressive stress $(\mathrm{MPa})$ plot from top of the clad to the substrate

Re-heating of previously cladded layers, resulted in coarsening of the microstructure and also precipitation of very fine carbides. EBSD analysis revealed the presence of $\mathrm{M}_{7} \mathrm{C}_{3}$ and $\mathrm{M}_{23} \mathrm{C}_{6}$ carbides within the matrix, as also reported by Shim et al. [25]. Pippel et al. [27], Novinrooz et al. [28] and Asadi et al. 29] reported TEM characterization of fine carbides in the HSS alloys in the size range of $20 \mathrm{~nm}$ to $300 \mathrm{~nm}$. These characterizations concluded the presence of $\mathrm{MC}, \mathrm{M}_{7} \mathrm{C}_{3}$ and $\mathrm{M}_{23} \mathrm{C}_{6}$ carbides. However, HRTEM of the matrix reported in the current investigation (fig,9 and fig 10 also found the presence of complex carbides, enriched with V, Mo, W and $\mathrm{Cr}$ which 
formed as fine precipitates. Measured lattice spacings of $0.15 \mathrm{~nm}$ to $0.26 \mathrm{~nm}$ of these precipitates are different from those of $\mathrm{MC}, \mathrm{M}_{2} \mathrm{C}, \mathrm{M}_{7} \mathrm{C}_{3}$ and $\mathrm{M}_{23} \mathrm{C}_{6}$.

During the cladding of thick multilayer coatings of LC1, a reduction in the micro-hardness of the previously cladded layers was observed. The hardness dropped cumulatively from a peak value of $795 \mathrm{HV}$ (top-layer) to 570 HV (intermediate-layer) after several cladding passes. Interestingly, microstructural characterization showed no substantial difference of phase fraction between the layers (see Table 3), indicating that the hardness drop can be attributed to the tempering of martensite during sequential cladding. Phenomenologically, during cladding of the subsequent layers, the heat accumulated during previously cladded layers transformed a part of retained austenite to martensite, but also resulted in tempering of existing lath martensitic matrix. The hardness of HSS is a function of tempering time and temperature, the softening of martensitic matrix was possibly due to shorter holding time [41]. Additionally, hardness drop could be result of yielding soft martensite (450 HV to $550 \mathrm{HV}$ ) during re-heating [42].

To overcome the tempering effects, a new alloy (LC2) has been developed through addition of Co, which was expected to stabilize the mobility of carbon in the solid solution. The Co addition changes the properties of the solid solution by increasing the binding strength and reduces the diffusion mobility of carbon [33, 43], as a result of which martensitic softening was slowed down. Jakubéczyová et al. [32] state that Co addition in HSS increases the secondary hardness by decreasing the solubility of $\mathrm{W}$ and Mo in the solid solution. Addition of Co reduces the growth and coalescence of carbides and also raises the austenising and melting temperatures [33]. According to EBSD analysis, Co stays in the solid solution with Fe and is also adsorbed at the surface of carbides (fig.8). Due to addition of Co in LC1, the resulting micro-hardness measurements of LC2 showed (1) an increase in coating hardness [843 HV vs. $808 \mathrm{HV}$ for LC1] and (2) a reduction in the hardness drop during sequential layer cladding [786 HV vs. $703 \mathrm{HV}$ for LC1].

Tensile testing of the sample combining LC1 clad tracks and $42 \mathrm{CrMo}_{4}$ substrate, showed a strong bonding between the thick coating and the substrate. In spite of $2.5 \%$ plastic strain, the tensile failures were attributed as brittle fractures in the laser clad portion of the sample. Examination of fractured surfaces indicated the presence of brittle cleavages with localized presence of dimpled surfaces [25], (fig,13). The mode of failure is apparently brittle in nature, with the inter granular failure due to presence of fine grain boundary carbides, same as reported by Telasang et al. [44]. 


\section{Conclusions}

Multilayer HSS alloys have been produced by laser cladding and characterized in terms of their microstructural evolution, hardness, stress state and tensile properties. A new modified HSS alloy has been developed based on:

(1) Laser cladding of thick (up to $20 \mathrm{~mm}$ ) multilayer coatings are successfully produced at a preheating temperature of $150{ }^{\circ} \mathrm{C}$. Massive martensitic transformation during cladding of HSS alloys, resulted in the compressive state of clads and suppressed the cracking.

(2) Re-heating during laser cladding of thick multilayer coatings of an Fe-CrMo-W-V alloy had a detrimental effect on the hardness of intermediate layers which was due to tempering of the martensite.

(3) Addition of $\mathrm{Co}$ in that alloy at the expense of Fe $\left(\mathrm{Fe}_{b a l-x}-\mathrm{Cr}-\mathrm{Mo}-\mathrm{W}-\mathrm{V}\right.$ $\mathrm{Co}_{x}$ ) significantly increased the overall coating hardness and overcame the reduction in hardness due to strengthening of the martensitic matrix.

(4) HRTEM of both alloys identified the presence of nanometer-sized carbides in the matrix enriched with $\mathrm{V}, \mathrm{W}, \mathrm{Cr}$ and Mo with lattice spacings of $0.15 \mathrm{~nm}$ to $0.26 \mathrm{~nm}$.

(5) Tensile testing results showed a strong adherence of thick multilayer coatings with the substrate. Due to presence of the martensitic matrix and hard carbides, the tensile failure was brittle.

\section{Acknowledgment}

This Project is funded by the European Research Fund for Coal and Steel (RFCS) under the grant agreement no. RFSR-CT-2015-00009.

\section{References}

[1] L. Dubourg, J. Archambeault, Technological and scientific landscape of laser cladding process in 2007, Surface and Coatings Technology 202 (2008) 5863-5869.

[2] F. Wirth, K. Wegener, A physical modeling and predictive simulation of the laser cladding process, Additive Manufacturing 22 (2018) 307-319.

[3] E. Toyserkani, A. Khajepour, S. Corbin, Laser Cladding, volume 119, 2004. 
[4] V. Ocelík, M. Eekma, I. Hemmati, J. De Hosson, Elimination of Start/Stop defects in laser cladding, Surface and Coatings Technology 206 (2012) 2403-2409.

[5] B. Bax, R. Rajput, R. Kellet, M. Reisacher, Systematic evaluation of process parameter maps for laser cladding and directed energy deposition, Additive Manufacturing 21 (2018) 487-494.

[6] E. M. Birger, G. V. Moskvitin, A. N. Polyakov, V. E. Arkhipov, Industrial laser cladding: Current state and future, Welding International 25 (2011) 234-243.

[7] L. Shepeleva, B. Medres, W. Kaplan, M. Bamberger, A. Weisheit, Laser cladding of turbine blades, Surface and Coatings Technology 125 (2000) 45-48.

[8] F. Wirth, S. Arpagaus, K. Wegener, Analysis of melt pool dynamics in laser cladding and direct metal deposition by automated high-speed camera image evaluation, Additive Manufacturing 21 (2018) 369-382.

[9] J. Zeisig, N. Schädlich, L. Giebeler, J. Sander, J. Eckert, U. Kühn, J. Hufenbach, Microstructure and abrasive wear behavior of a novel FeCrMoVC laser cladding alloy for high-performance tool steels, Wear 382-383 (2017) 107-112.

[10] H. Phan, A. Tieu, H. Zhu, B. Kosasih, Q. Zhu, A. Grima, T. Ta, A study of abrasive wear on high speed steel surface in hot rolling by Discrete Element Method, Tribology International 110 (2017) 66-76.

[11] H. J. Niu, I. T. H. Chang, Microstructural evolution during laser cladding of M2 high-speed steel, Metallurgical and Materials Transactions A 31 (2000) 2615-2625.

[12] G. F. Sun, K. Wang, R. Zhou, A. X. Feng, W. Zhang, Effect of different heat-treatment temperatures on the laser cladded M3:2 high-speed steel, Materials and Design 65 (2015) 606-616.

[13] H. Fu, Q. Xiao, J.-D. Xing, A study on the crack control of a high-speed steel roll fabricated by a centrifugal casting technique, Materials Science and Engineering: A 474 (2008) 82-87. 
[14] N. Song, Y. Luan, Y. Bai, Z. Xu, X. Kang, D. Li, Numerical Simulation of Solidification of Work Roll in Centrifugal Casting Process, Journal of Materials Science \& Technology 28 (2012) 147-154.

[15] K. C. Hwang, S. Lee, H. C. Lee, Effects of alloying elements on microstructure and fracture properties of cast high speed steel rolls: Part I: Microstructural analysis, Materials Science and Engineering: A 254 (1998) 282-295.

[16] M. Boccalini, H. Goldenstein, Solidification of high speed steels, International Materials Reviews 46 (2001) 92-115.

[17] M. Nilsson, M. Olsson, Microstructural, mechanical and tribological characterisation of roll materials for the finishing stands of the hot strip mill for steel rolling, Wear 307 (2013) 209-217.

[18] J. Mazumder, A. Schifferer, J. Choi, Direct materials deposition: Designed macro and microstructure, Materials Research Innovations 3 (1999) 118-131.

[19] K.-H. Lee, S.-W. Choi, J. Suh, C.-Y. Kang, Effect of laser power and powder feeding on the microstructure of laser surface alloying hardened H13 steel using SKH51 powder, Materials \& Design 95 (2016) 173-182.

[20] A. Suárez, J. Amado, M. Tobar, A. Yáñez, E. Fraga, M. Peel, Study of residual stresses generated inside laser cladded plates using FEM and diffraction of synchrotron radiation, Surface and Coatings Technology 204 (2010) 1983-1988.

[21] F. Brückner, D. Lepski, E. Beyer, Modeling the Influence of Process Parameters and Additional Heat Sources on Residual Stresses in Laser Cladding, Journal of Thermal Spray Technology 16 (2007) 355-373.

[22] Y. Sano, T. Hattori, M. Haga, Characteristics of High-Carbon High Speed Steel Rolls for Hot Strip Mill, ISIJ International 32 (1992) 11941201.

[23] D.-S. Shim, G.-Y. Baek, S.-B. Lee, J.-H. Yu, Y.-S. Choi, S.-H. Park, Influence of heat treatment on wear behavior and impact toughness of AISI M4 coated by laser melting deposition, Surface and Coatings Technology 328 (2017) 219-230. 
[24] J. Jiang, G. Lian, M. Xu, C. Li, B. Chen, B. Li, Influence of Preheating Temperature on Mechanical Properties of Laser Cladding Layer, In ASME 2016 11th International Manufacturing Science and Engineering Conference, Virginia, USA (2016) 1-6.

[25] D. S. Shim, G. Y. Baek, E. M. Lee, Effect of substrate preheating by induction heater on direct energy deposition of AISI M4 powder, Materials Science and Engineering A 682 (2017) 550-562.

[26] V. Ocelík, U. de Oliveira, J. T. M. De Hosson, Thick tool steel coatings with laser cladding, in: Transactions on Engineering Sciences, volume 55 of WIT Transactions on Engineering Sciences, Vol 55, WIT Press, Southampton, UK, 2007, pp. 13-22.

[27] E. Pippel, J. Woltersdorf, G. Pöckl, G. Lichtenegger, Microstructure and nanochemistry of carbide precipitates in high-speed steel S 6-5-2-5, Materials Characterization 43 (1999) 41-55.

[28] A. J. Novinrooz, S. Moniri, M. Asadi Asadabad, A. Hojabri, The Study of Nano-Sized Carbide Particles Formed in Fe-Cr-W-V Alloy, Journal of Materials Engineering and Performance 21 (2012) 1440-1446.

[29] M. A. Asadabad, S. Kheirandish, A. Novinrooz, Identification of Nanometric Carbide Precipitates in Fe-Cr-W-V System, Synthesis and Reactivity in Inorganic, Metal-Organic and Nano-Metal Chemistry 39 (2009) 322-326.

[30] A. Weisheit, G. Backes, R. Stromeyer, A. Gasser, K. Wissenbach, R. Poprawe, Powder injection: the key to reconditioning and generating components using laser cladding, Proceedings of the International Congress on Advanced Materials and Processes (2001) 1-7.

[31] I. Hemmati, V. Ocelik, J. T. M. De Hosson, Correlation Between Cladding Speed, Microstructure and Hardness of Laser-Deposited Steel Coatings : the Role of Strengthening Mechanism, ICALEO 2014, San Diego 23 (2014) 403-409.

[32] M. Jakubéczyová, D. Fáberová, Mechanical properties and surface treatment PM cobalt high speed steels, Powder Metallurgy Progress 2 (2002) 188-197. 
[33] A. P. Gulyaev, I. K. Kupalova, Effect of cobalt on the structure and properties of high-speed steels, Metal Science and Heat Treatment 12 (1970) 666-671.

[34] U. de Oliveira, V. Ocelík, J. De Hosson, Residual stress analysis in Cobased laser clad layers by laboratory X-rays and synchrotron diffraction techniques, Surface and Coatings Technology 201 (2006) 533-542.

[35] G. Telasang, J. Dutta Majumdar, G. Padmanabham, M. Tak, I. Manna, Effect of laser parameters on microstructure and hardness of laser clad and tempered AISI H13 tool steel, Surface and Coatings Technology 258 (2014) 1108-1118.

[36] P. Kattire, S. Paul, R. Singh, W. Yan, Experimental characterization of laser cladding of CPM 9V on $\mathrm{H} 13$ tool steel for die repair applications, Journal of Manufacturing Processes 20 (2015) 492-499.

[37] P. J. Withers, H. K. D. H. Bhadeshia, Residual stress Part 1 Measurement techniques, Materials Science and Technology 17 (2001) 355-365.

[38] Y. Ma, X. Yao, D. Zhang, Axially symmetrical stresses measurement in the cylindrical tube using DIC with hole-drilling, Optics and Lasers in Engineering 66 (2015) 174-180.

[39] G. S. Schajer, Measurement of Non-Uniform Residual Stresses Using the Hole-Drilling Method. Part IStress Calculation Procedures, Journal of Engineering Materials and Technology 110 (1988) 338.

[40] N. S. Bailey, C. Katinas, Y. C. Shin, Laser direct deposition of AISI H13 tool steel powder with numerical modeling of solid phase transformation, hardness, and residual stresses, Journal of Materials Processing Technology 247 (2017) 223-233.

[41] S. Sackl, G. Kellezi, H. Leitner, H. Clemens, S. Primig, Martensitic Transformation of a High-speed Tool Steel During Continuous Heat Treatment, Materials Today: Proceedings 2 (2015) S635-S638.

[42] J. Briki, S. Ben Slima, A New Continuous Cooling Transformation Diagram for AISI M4 High-Speed Tool Steel, Journal of Materials Engineering and Performance 17 (2008) 864-869. 
[43] Y. Zhang, K. Shimizu, K. Kusumoto, H. Hara, C. Higuchi, Effect of Co Addition on High Temperature Erosive Wear Characteristics of Fe-CCr-Mo-W-V Multi-Component White Cast Iron, Wear 376-377 (2017) $452-457$.

[44] G. Telasang, J. Dutta Majumdar, G. Padmanabham, I. Manna, Structureproperty correlation in laser surface treated AISI H13 tool steel for improved mechanical properties, Materials Science and Engineering: A 599 (2014) 255-267. 